\title{
Phenotypic Variation of $46, X X$ Late Identified Congenital Adrenal Hyperplasia among Indonesians
}

\author{
Achmad Zulfa Juniarto, ${ }^{1}$ Maria Ulfah, ${ }^{1}$ Mahayu Dewi Ariani, ${ }^{1}$ Agustini Utari, ${ }^{1,2}$ Sultana MH Faradz ${ }^{1}$ \\ ${ }^{1}$ Center for Biomedical Research (CEBIOR), Faculty of Medicine Diponegoro University, Semarang, Indonesia \\ ${ }^{2}$ Division of Pediatric Endocrinology, Department of Pediatrics, Faculty of Medicine, Diponegoro University, Semarang, Indonesia
}

\begin{abstract}
Objectives. To describe the phenotype variation in Indonesian 46,XX late-identified congenital adrenal hyperplasia $(\mathrm{CAH})$ and the correlation between 17-hydroxyprogesterone (17-OHP) and genital virilization.

Methodology. Retrospective study of 39 cases with five salt-wasting (SW) and 34 simple virilizing (SV) types.

Results. The median age of the patients was 9.83 years (range, 0.58 to 44 years) with Prader score 2 to 5 . Clitoromegaly (100\%) and skin hyperpigmentation (87\%) were the most common features. Lack of breast development (Tanner 1 to 2 ) and menstrual disorders occurred in 9 patients (teenagers and adults). Short stature (6), low voice (14), prominent Adam's apple (9) and hirsutism (4) were found only in SV types. Rapid growth (7) and precocious puberty (8) were identified in children. Male gender on admission was found in 13 patients. The mean of 17-OHP level was 304.23 $\mathrm{nmol} / \mathrm{L}$ [standard deviation (SD) $125.03 \mathrm{nmol} / \mathrm{L}$ ]. There was no correlation between 17-OHP levels and virilization $(r=0.19, p>0.05)$.

Conclusion. Late-identified CAH showed severe virilization and irreversible sequelae, with clitoromegaly and skin hyperpigmentation as the most commonly seen features. Masculinization of CAH females created uncertainty with regard to sex assignment at birth, resulting in female, male and undecided genders. There is no significant correlation between 17-OHP levels with the degree of virilization in $\mathrm{CAH}$ females.
\end{abstract}

Key words: $\mathrm{CAH}$, late-identified, phenotype, virilization

\section{INTRODUCTION}

Congenital adrenal hyperplasia is a leading cause of $46, \mathrm{XX}$ disorders of sex development (DSD) resulting from a deficiency of enzymes required for cortisol and aldosterone biosynthesis. More than $90 \%$ cases have $21-$ hydroxylase deficiency (21-OHD) and mutations in the CYP21A2 gene, which is located on the short arm of chromosome 6 (6p21.3). ${ }^{1,2}$ Affected females are born with various degrees of virilization, as a result of prenatal androgen exposure. Aside from 21-OHD, virilization in $46, \mathrm{XX}$ individuals with $\mathrm{CAH}$ is also caused by $11 \beta-$ hydroxylase deficiency (11 $\beta-O H D)$, P450 oxidoreductase deficiency (POR) and 3 $\beta$-hydroxysteroid dehydrogenase deficiency (3 $\beta$-HSD). ${ }^{2,3,4}$

Classic CAH can be further divided into salt-wasting and simple virilizing types. Virilization in a female manifests as clitoromegaly, acne, hirsutism and low voice. At puberty, normal feminization of girls fails to occur, usually presenting with lack of breast development or absence of menstruation. ${ }^{3,4}$ Elevation of $17-\mathrm{OHP}$ in $\mathrm{CAH}$ leads to

ISSN 0857-1074 (Print) I ISSN 2308-118x (Online)

Printed in the Philippines

Copyright (c) 2018 by the JAFES

Received: October 24, 2017. Accepted: January 9, 2018.

Published online first: March 12, 2018.

https://doi.org/10.15605/jafes.033.01.02 increased androgen levels, but the relationship between 17-OHP and virilization phenotype has not been consistent as seen in previous studies. ${ }^{2,5}$

The incidence of $\mathrm{CAH}$ in the general population is approximately 1 in 16,000 on screened newborns worldwide, and carriers are present in 1:60.6,7 Data from our center from 2004 to 2016 show that there are 84 patients with $\mathrm{CAH}$, consisting of a wide age range of 3 days to 44 years old. Majority of the patients seen have never received any specific treatment for $\mathrm{CAH}$. Genital ambiguity was the most common reason for physician consult in female patients.

Delayed diagnosis and treatment of $\mathrm{CAH}$ in children is common in Indonesia. It is frequent especially for SV or SW types who develop adrenal crises without a definite diagnosis due to the absence of newborn screening. ${ }^{8}$ In Indonesia, newborn screening for $\mathrm{CAH}$ is not yet available, as basic treatment and hormonal tests are not provided in public hospitals with health insurance services. Ethically, it cannot be provided yet because

Corresponding Author: Prof. Sultana MH Faradz MD, PhD

Center for Biomedical Research

Faculty of Medicine Diponegoro University

Jl. Prof. Sudarto SH, Tembalang, Semarang Indonesia 50275

Tel. No.: 62-24-8412311

Fax No.: 62-24-8454714

E-mail: sultanafaradz@gmail.com

ORCID iD: https://orcid.org/0000-0002-6059-6075 
medications such as hydrocortisone and fludrocortisone are not available. In developed countries, a patient with $\mathrm{CAH}$ is often diagnosed early in life by neonatal screening programs. ${ }^{9}$

\section{OBJECTIVES}

1. To describe the phenotype variation in Indonesian 46,XX late-identified CAH, which is rarely reported in other countries, and;

2. To identify the correlation of $17-\mathrm{OHP}$ and genital virilization.

\section{METHODOLOGY}

\section{Study design}

This is a descriptive study.

\section{Patients and methods}

From 2004 to 2016, we gathered 84 patients with a diagnosis of $\mathrm{CAH}$, evaluated under the clinical management of the multidisciplinary DSD team of the Dr. Kariadi Hospital and Faculty of Medicine Diponegoro University. Thirty-nine patients were enrolled in this study.

$\mathrm{CAH}$ was diagnosed based on the clinical manifestations and elevated serum levels of 17-OHP. The inclusion criteria were $46, \mathrm{XX}$ karyotype and age 6 months or older at first visit to our center. Patients who underwent corrective genital surgery before their first visit to our center were excluded.

Medical records were reviewed to gather data including age at diagnosis, anthropometrics, appearance of genitalia, Prader score, Tanner stage, skin hyperpigmentation, acne, hirsutism, and low voice with or without Adam's apple, menstrual disorders and family history (pedigree). Details and additional information were verified with the patient or parent.

\section{Ethical considerations}

This study was approved by the Medical Ethics Committee and informed consent was obtained from all patients and parents.

\section{RESULTS}

\section{Clinical findings}

Thirty-nine patients (5 SW and $34 \mathrm{SV}$ ) fulfilled the inclusion criteria, with a mean age of 9.83 ( $S D \pm 9.42$ years). There were 9 adults and 30 children. Physician-diagnosed SW type was significantly younger compared to SV type (mean age 0.58 versus 7.25 years, $\mathrm{p}<0.05$ ). The phenotype variation of late identified CAH are shown in Table 1 . The most frequent clinical manifestations on both SW and SV types were clitoromegaly $(100 \%)$ and generalized skin hyperpigmentation mainly around the genital area (87\%). Nine patients with ages over 13 years showed lack of breast development (breast Tanner stage 1 to 2). Menstrual disorders included primary amenorrhea (67\%) and late menarche occurring at age over 15 years (33\%, 15 to 18 years). Precocious puberty (23.3\%), defined as premature pubic hair growth, was evident by 3 years old. Fourteen patients had low voice $(35.9 \%)$, 9 of which had prominent Adam's apple. Four patients had hirsutism (10.3\%), all of whom were SV type. Two patients had acne problems. Eight children had height measurements above the 97th percentiles for age in the Chinese Growth chart (26.7\%), the

\begin{tabular}{|c|c|c|c|c|}
\hline Clinical findings & SWb type $(n=5)$ & $S^{c}$ type $(n=34)$ & Total & p-value \\
\hline Clitoromegaly (\%) & $5 / 5(100)$ & $34 / 34(100)$ & $39 / 39(100)$ & 0 \\
\hline Hyperpigmentation (\%) & $5 / 5(100)$ & $29 / 34(85.4)$ & $34 / 39(87.2)$ & $0.6^{*}$ \\
\hline Hirsutism (\%) & $0 / 5$ & $4 / 34(11.7)$ & $4 / 39(10.3)$ & - \\
\hline Low voice $(\%)$ & $1 / 5(20)$ & $13 / 34(38.2)$ & $14 / 39(35.9)$ & - \\
\hline With Adam's apple (\%) & $0 / 5$ & $9 / 13(69.2)$ & $9 / 39(23.1)$ & - \\
\hline Acne $(\%)$ & $0 / 5$ & $2 / 34(5.8)$ & $2 / 39(5.1)$ & - \\
\hline Short stature & & & & - \\
\hline Children & $0 / 5$ & $1 / 25(4.0)$ & $1 / 30(3.3)$ & \\
\hline Adult & $0 / 5$ & $7 / 9(77.8)$ & $7 / 9(77.8)$ & \\
\hline \multicolumn{5}{|l|}{ Age 13 years or less } \\
\hline Rapid growth & $1 / 5(20)$ & $6 / 25(24)$ & $7 / 30(23.3)$ & - \\
\hline Precocious puberty & $2 / 5(40)$ & $6 / 25(24)$ & $8 / 30(26.7)$ & - \\
\hline \multicolumn{5}{|l|}{ Age over 13 years } \\
\hline Lack of breast development (Tanner 1 to 2 ) & 0 & $9 / 9(100)$ & $9 / 9(100)$ & - \\
\hline Menstrual disorders & 0 & $9 / 9(100)$ & $9 / 9(100)$ & - \\
\hline \multicolumn{5}{|l|}{ Genitalia status } \\
\hline Clitoris/phallus length $(\mathrm{cm})$ & $4.8 \pm 2.4$ & $4.24 \pm 1.2$ & $4.3 \pm 1.4$ & $0.3^{\mathrm{e}}$ \\
\hline Scrotalization & $3 / 5(60)$ & $21 / 34(62)$ & $24 / 39(61.5)$ & $0.6^{\mathrm{d}}$ \\
\hline Complete labial fusion & $1 / 5(20)$ & $6 / 34(17.9)$ & $7 / 39(44)$ & $1^{d}$ \\
\hline Rudimentary labia minora & $4 / 5(80)$ & $23 / 34(67.6)$ & $27 / 39(61.5)$ & $0.3^{\mathrm{d}}$ \\
\hline Prader score & Stage $3(60)$ & Stage $4(38.2)$ & Stage $3(36)$ & $0.7^{f}$ \\
\hline Mean serum 17-OHP level, nmol/L & 391.00 & 291.47 & 304.23 & $0.3^{f}$ \\
\hline $\begin{array}{l}{ }^{\text {a }} \mathrm{CAH} \text {, congenital adrenal hyperplasia } \\
{ }^{\mathrm{b}} \mathrm{SW} \text {, salt-wasting } \\
{ }^{\mathrm{c}} \mathrm{SV} \text {, simple virilizing } \\
{ }^{\mathrm{d}} \text { Fisher exact test } \\
\text { e T-test } \\
{ }^{\mathrm{f}} \text { Mann-Whitney test }\end{array}$ & & & & \\
\hline
\end{tabular}


Table 2. Gender assignment after final examination

\begin{tabular}{|c|c|c|c|c|}
\hline \multirow{2}{*}{ Patient number } & \multicolumn{2}{|c|}{ Gender and age on admission } & \multicolumn{2}{|c|}{ Gender and age after final examination } \\
\hline & Gender & Age $\left(y .0^{* *}\right)$ & Gender & Age (y.o) \\
\hline 1 & Male & 17 & Male & 18 \\
\hline 2 & Female & 11 & Female & 12 \\
\hline 3 & Female & 33 & Female & 33.5 \\
\hline 4 & Female & 6 & Female & 6.5 \\
\hline 5 & Female & 7 & Female & 8 \\
\hline 6 & Female & 7 & Female & 8 \\
\hline 7 & Female & 4 & Female & 5 \\
\hline 8 & Male & 3 & Male & 4 \\
\hline 9 & Female & 1.5 & Female & 2 \\
\hline 10 & Female & 1.9 & Female & 2 \\
\hline 11 & Female & 10 & Female & 11 \\
\hline 12 & Female & 3 & Female & 3.5 \\
\hline 13 & Female & 7 & Female & 8 \\
\hline 14 & Female & 6 & Female & 6.5 \\
\hline 15 & Male & 24 & Male & 25 \\
\hline 16 & Female & 7.5 & Female & 8 \\
\hline 17 & Female & 4 & Female & 4.5 \\
\hline 18 & Male* & 7.75 & Male & 8 \\
\hline 19 & Male & 8 & Male & 8.5 \\
\hline 20 & Female & 23.5 & Female & 24 \\
\hline 21 & Female & 18 & Female & 18 \\
\hline 22 & Male & 1.5 & Female & 2 \\
\hline 23 & Female & 15 & Female & 16 \\
\hline 24 & Male & 8.5 & Male & 9.5 \\
\hline 25 & Female & 17 & Female & 17.5 \\
\hline 26 & Female & 3 & Female & 3.5 \\
\hline 27 & undecided & 2 & undecided & 3 \\
\hline 28 & Male & 44 & Male & 46 \\
\hline 29 & Male* & 1 & Female & 1.5 \\
\hline 30 & Male* & 0.58 & Female & 1 \\
\hline 31 & Male & 10 & Male & 10.5 \\
\hline 32 & Female & 3 & Female & 4 \\
\hline 33 & Female & 19 & Female & 20 \\
\hline 34 & Female $^{*}$ & 5.67 & Female & 6.5 \\
\hline 35 & Female & 21.5 & Female & 22 \\
\hline 36 & Male & 8 & Male & 8.5 \\
\hline 37 & Female & 7 & Female & 8 \\
\hline 38 & Male* & 5 & Female & 5.5 \\
\hline 39 & Female & 1.8 & Female & 2 \\
\hline
\end{tabular}

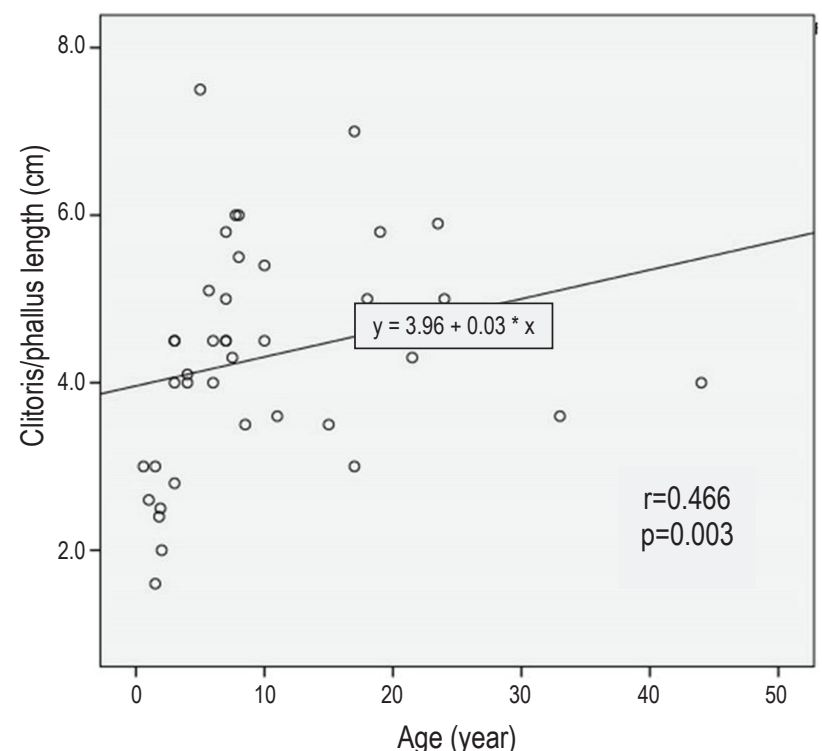

Figure 1. Relationship between age and phallus length in late-identified $\mathrm{CAH}$.

available reference for Asian populations, indicative of rapid growth. ${ }^{10}$ Short stature, defined as less than the $3^{\text {rd }}$ percentiles of the Chinese Growth Chart, occurred in 6 adult patients (75\%). Of this group, one child had accelerated epiphyseal maturation, with bone age at 17 to 18 years.

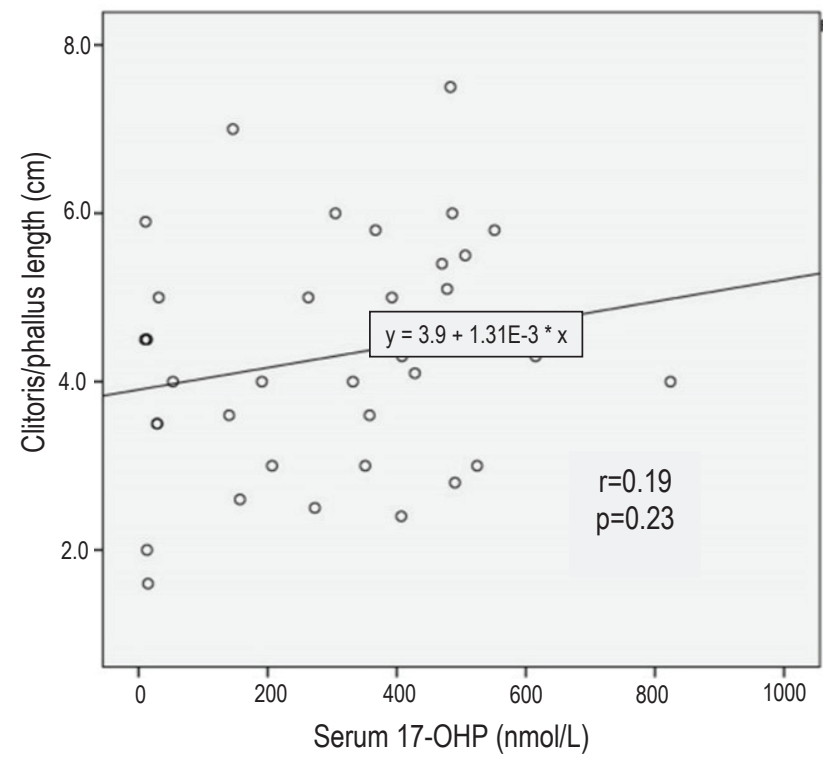

Figure 2. Relationship between serum 17hydroxyprogesterone (17-OHP) levels and phallus length in late-identified $\mathrm{CAH}$.

The next most common dysmorphology was rudimentary labia minora, seen in $80 \%$ of SW and $67 \%$ of SV types ( $p>0.05)$. However, clitoral/phallus length was not significantly different between SW and SV types, with mean length $4.8 \mathrm{~cm}$ and $4.24 \mathrm{~cm}$, respectively ( $>0.05$ ). We 


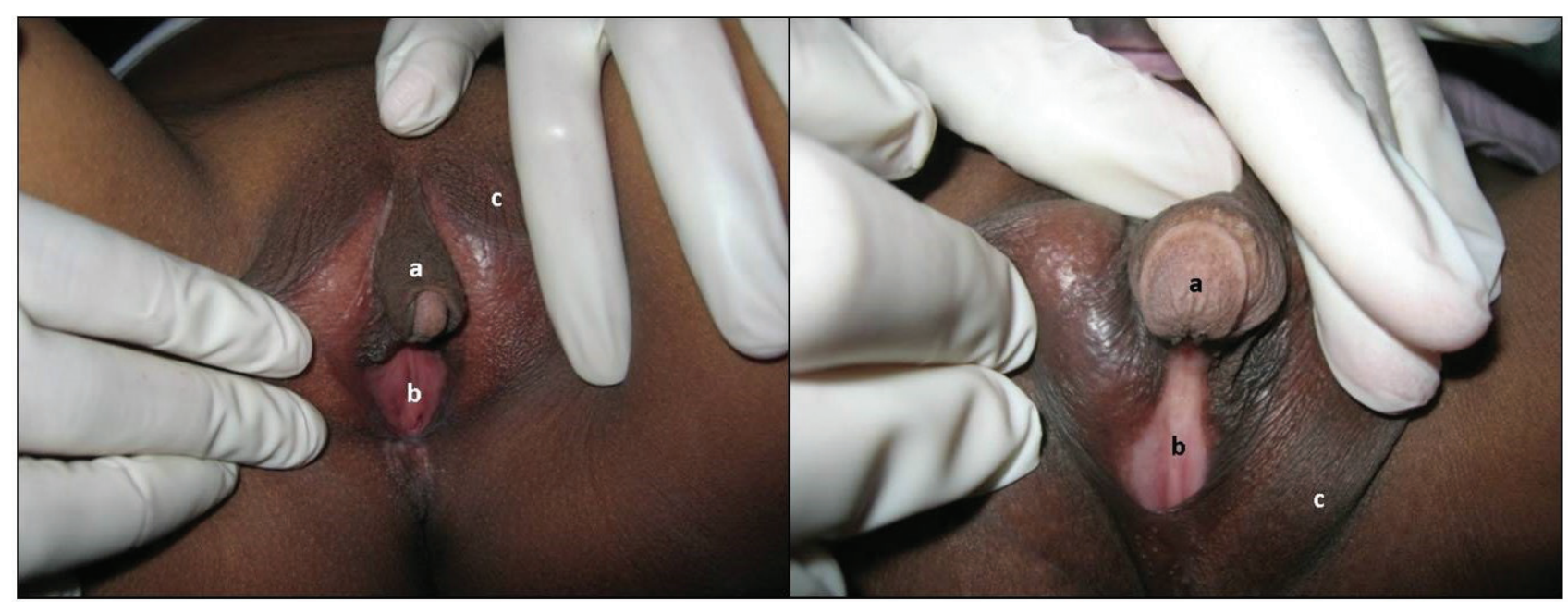

Figure 3. Virilized external genitalia in 2 female siblings showing clitoromegaly (a), presence of vaginal introitus (b), and hyperpigmentation (c).

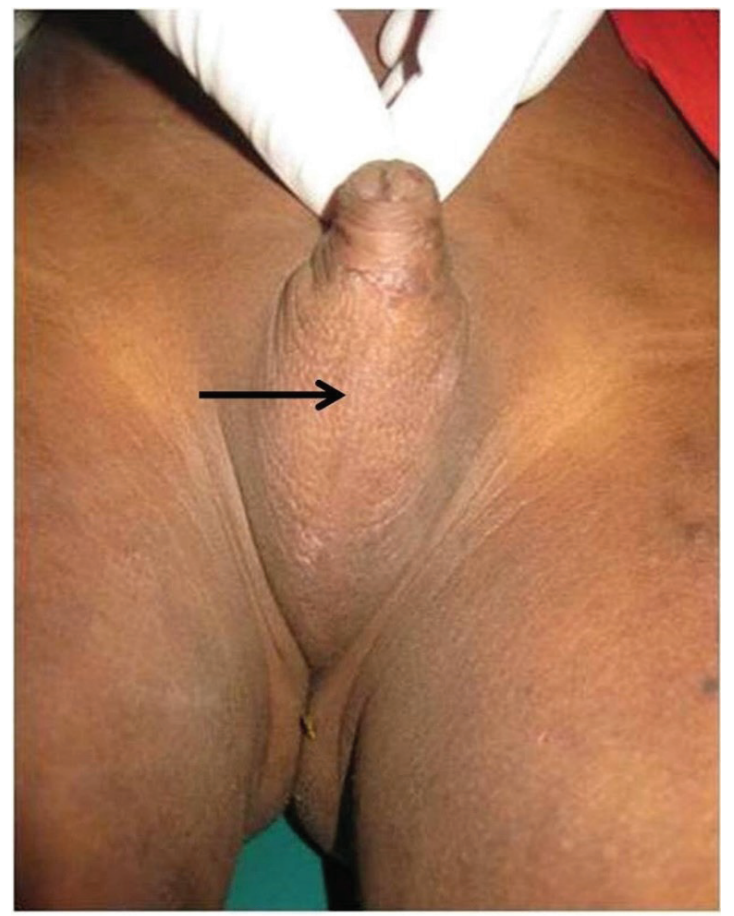

Figure 4. An 8.5-year-old child assigned to male gender with $46, \mathrm{XX}$ late-identified $\mathrm{CAH}$. There is complete labial fusion (arrow) resembling a scrotum.

found a good correlation between age and phallus length in late-identified CAH ( $\mathrm{r}=0.466, \mathrm{p}<0.05)$ (Figure 1). More than $50 \%$ of both SW type and SV type CAH had labial scrotalization. Complete labial fusion was more frequent in SW (20\%) compared to SV (17.9\%) ( $p>0.05)$.

All patients had genital ambiguity, with a median Prader score of 3 and 4 in SW and SV types, respectively. Thirteen patients $(33 \%)$ reveal male gender and four patients with male gender of five SW-type on their first visit and one SV type patient had undetermined gender. However, after undergoing thorough physical and laboratory examination and genetic counseling, four patients decided to change their gender from male to female (Table 2).

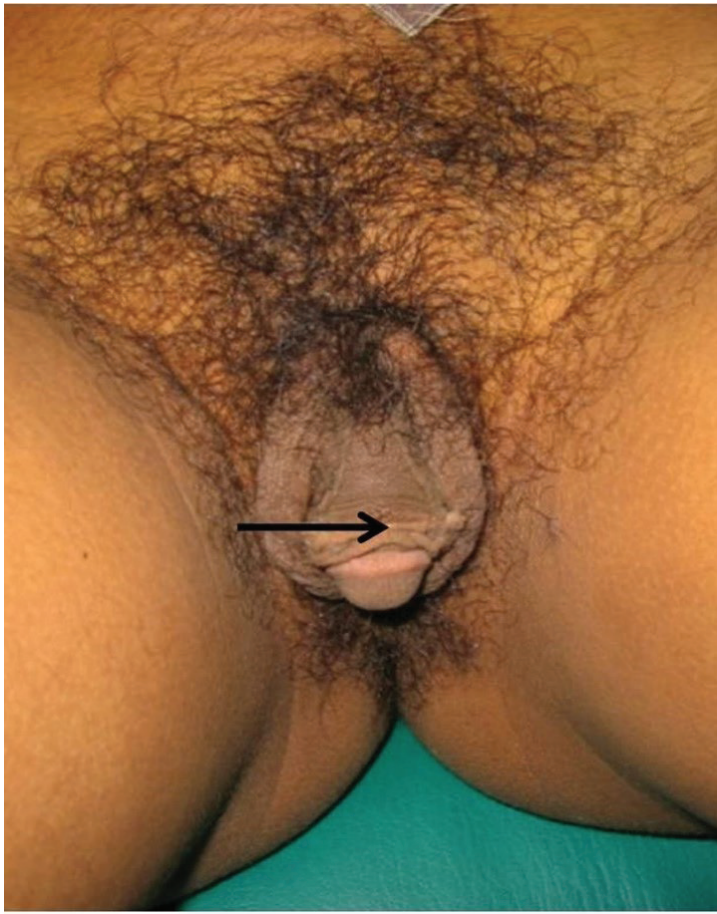

Figure 5. A 24-year-old adult assigned to male gender with $46, \mathrm{XX}$ late-identified $\mathrm{CAH}$. There is a big phallus (arrow) with scrotalization.

\section{Correlation of 17-OHP with phallus length}

All patients had elevated blood levels of 17-OHP. Based on Spearman's correlation coefficient test, there was no correlation between 17-OHP level and phallus length $(\mathrm{r}=0.19, \mathrm{p}>0.05)$ (Figure 2).

\section{DISCUSSION}

The mean age of presentation of patients in our study is nine years, quite different from data from Western populations. ${ }^{11}$ Recognition is frequently late due to lack of knowledge of medical providers, especially in remote regions; lack of awareness of parents to seek medical management; unavailability of neonatal screening in 
Indonesia; and early death of affected babies before diagnosis.

There are significant differences in the number of patients and their age at diagnosis in SW and SV types in our study, in contrast to other published reports. ${ }^{12}$ This discrepancy suggests that more of SW type CAH patients died from adrenal crises before being diagnosed. Identifying newborn girls with signs and symptoms of $\mathrm{CAH}$ is not difficult because of genital ambiguity and salt wasting symptoms in the SW type. In newborn boys, the diagnosis is challenging because of the absence of ambiguous genitalia, especially in the SV type. Moreover, $\mathrm{CAH}$ in Indonesia is still unfamiliar for many medical practitioners, such as general practitioners or midwives. Factors that may lead to late diagnosis and treatment include high cost and limited facilities for hormonal analysis to detect $\mathrm{CAH}$, and the difficult access to appropriate medications.

Clinical variations depend on the degree of hormonal disruption, and timeliness and regularity of treatment. ${ }^{13}$ Virilization is very prominent in late-identified females with $\mathrm{CAH}$ due to the untreated condition (Figure 3). There is a good correlation between age and phallus length in late-identified $\mathrm{CAH}$, indicating that older untreated $\mathrm{CAH}$ females are more virilized. Androgen exposure in these girls start from the prenatal period and persist until they receive treatment. ${ }^{14}$ In our study, androgen excess in untreated females resulted to progressive virilization of the clitoris, hyperpigmentation, lack of breast development, primary amenorrhea, delayed menarche, premature pubic hair growth, hirsutism, low voice with or without prominent Adam's apple and short stature. These observations are comparable with findings in previous studies. ${ }^{15,16}$

In our study, thirty-three percent of patients were considered male because of the presence of male-looking genitalia (clitoromegaly resembling penis, scrotalization with or without complete labial fusion) and the absence of treatment (Figures 4 and 5). This emphasizes the need for a thorough urogenital examination in the neonatal period for patients with DSD. Chromosomal and hormonal analyses should be performed on neonates with ambiguous genitalia to facilitate gender assignment. ${ }^{17}$

Precocious puberty in female CAH patients are recognized by premature pubic hair growth occurring before 8 years of age and rapid growth. ${ }^{18}$ In the same study, patients treated after age one year have a higher risk for precocious puberty; for SV type boys, this risk was apparent even in those who received treatment at the age of 6 months. ${ }^{18}$ We found similar findings with Hargitai et al., our SV type children showed accelerated growth patterns after 3 years old, while the final height of adult patients leading to short stature was reduced compared to the standard population and their respective target heights. ${ }^{19}$ Bone age determination may be able to show accelerated epiphyseal maturation. Unfortunately, these results were not available in all our CAH children, due to financial constraints and limited facilities.

In our study, all late-identified CAH patients had elevated blood levels of 17-OHP. The 17-OHP levels were weakly correlated with phallus length $(\mathrm{r}=0.19)$. However, there was no clear relationship between 17-OHP levels and virilization of external genitalia, similar to findings by Rocha et al. ${ }^{20}$

Genetic counseling for families and patients is advised to explain the clinical manifestations, mode of inheritance, recurrence risk and consequences of CAH. Some challenges to our work include varied cultural beliefs within families, patient discrimination and taboos pertaining to their masculinized condition, and the unavailability of a genetic counselor. ${ }^{21}$ Gender assignment is still a dilemma: some of the children were raised as males, females or left undecided. Late-identified CAH females with progressive virilization should undergo psychological evaluation to assess their emotional condition and gender identity.

\section{CONCLUSION}

In our study, the most common clinical features in lateidentified Indonesian $\mathrm{CAH}$ patients were clitoromegaly and skin hyperpigmentation. Clinical features such as genital virilization, low voice, Adam's apple and short stature in adults were permanent phenotypes, indicating the severity and irreversibility of virilization despite medication. There was no correlation between of 17-OHP levels and virilization. There is a general lack of awareness of medical personnel, family members and patients regarding $\mathrm{CAH}$ and its effects. The high cost and limited availability of laboratory tests and difficult access to medications pose significant challenges as well. Improvement in the clinical recognition of suspected $\mathrm{CAH}$ patients is important in our Indonesian clinical setting. Genetic counseling is crucial in the management of $\mathrm{CAH}$, especially for gender determination. Newborn screening should be included in the improvement of health policy in Indonesia.

\section{Acknowledgments}

We thank the multidisciplinary DSD team of Dr. Kariadi Hospital - FMDU and the staff in CEBIOR for their help with the patients and laboratory work. We would like to thank all the families involved in our study. The author (MU) is a recipient of the Beasiswa Unggulan BPKLN fellowship from the Indonesian Ministry of Education and Culture.

\section{Statement of Authorship}

All authors certified fulfillment of ICMJE authorship criteria.

\section{Author Disclosure}

The authors declared no conflict of interest. 


\section{Funding Source}

This study was supported by Competitive Research Grant from the Indonesian Ministry of Research, Technology and Education DIPA number 023.04.2.673453/2015 and number 022/SP2H/LT/ DRPM/II/2016.

\section{References}

Reference entries \#11, 13 and 17 were not cited in the text.

1. Ekenze SO, Nwangwu EI, Amah CC, Agugua-Obianyo NE, Onuh AC, Ajuzieogu OV. Disorders of sex development in a developing country: Perspectives and outcome of surgical management of 39 cases. PediatrSurg Int. 2015;31(1):93-9. PMID: 25326123. https://doi. org/1007/s00383-014-3628-1.

2. Speiser PW, White PC. Congenital adrenal hyperplasia. N Engl J Med. 2003;349(8):776-88. PMID: 12930931. https://doi.org/10.1056/ NEJMra021561.

3. Mooij $\mathrm{CF}$, van Herwaarden AE, Claahsen-van der Grinten HL. Disorders of adrenal steroidogenesis: Impact on gonadal function and sex development. Pediatr Endocrinol Rev. 2016;14(2):109-28. PMID: 28508605. https://10.17458/PER.2016.MEC.DisordersofAdrenal.

4. Auchus RJ. The classic and nonclassic congenital adrenal hyperplasias. Endocr Pract. 2015;21(4):383-9. PMID: 25536973. https://doi.org/10.4158/EP14474.RA.

5. Sugiyama Y, Mizuno H, Hayashi Y, et al. Severity of virilization of external genitalia in Japanese patients with salt-wasting 21hydroxylase deficiency. Tohoku J Exp Med. 2008;215(4):341-8. PMID: 18679008.

6. van der Kamp HJ, Wit JM. Neonatal screening for congenital adrenal hyperplasia. Eur J Endocrinol. 2004;151(Suppl 3):U71-5. PMID: 15554889.

7. Trapp CM, Oberfield SE. Recommendations for treatment of nonclassic congenital adrenal hyperplasia (NCCAH): An update. Steroids. 2012;77(4):342-6. PMID: 22186144. PMCID: PMC3638754. NIHMSID: NIHMS461777.

8. Juniarto AZ, van der Zwan YG, Santosa A, et al. Application of the new classification on patients with a disorder of sex development in Indonesia. Int J Endocrinol. 2012;2012:237084. PMID: 22253624. PMCID: PMC3255103. https://doi.org/10.1155/2012/237084.

9. Ediati A, Faradz SM, Juniarto AZ, van der Ende J, Drop SL, Dessens AB. Emotional and behavioral problems in late-identified Indonesian patients with disorders of sex development. J Psychosom Res. 2015;79(1):76-84. PMID: 25563666. https://doi.org/10.1016/j.jpsychores. 2014.12.007.

10. Chang KSF, Lee MMC, Low WD. Standards of height and weight of Southern Chinese Children. Far East Med J. 1965;1:101-9.

11. Juniarto AZ, van der Zwan YG, Santosa A, et al. Hormonal evaluation in relation to phenotype and genotype in 286 patients with a disorder of sex development from Indonesia. Clin Endocrinol (Oxf). 2016;85(2):247-57. PMID: 26935236. https://doi.org/10.1111/cen.13051.

12. Dörr HG, Odenwald B, Nennstiel-Ratzel U. Early diagnosis of children with classic congenital adrenal hyperplasia due to 21 hydroxylase deficiency by newborn screening. Int J Neonatal Screen. 2015;1:36-44. https://doi.org/10.3390/ijns1010036.

13. Knowles RL, Khalid JM, Oerton JM, Hindmarsh PC, Kelnar CJ, Dezateux C. Late clinical presentation of congenital adrenal hyperplasia in older children: Findings from nationalpaediatric surveillance. Arch Dis Child. 2014;99(1):30-4. PMID: 24043550. PMCID: PMC3888619. https://doi.org/10.1136/archdischild-2012303070.

14. Ambroziak U, Bednarczuk T, Ginalska-Malinowska M, et al. Congenital adrenal hyperplasia due to 21-hydroxylase deficiency management in adults. Endokrynol Pol. 2010;61(1):142-55. PMID: 20205117.

15. Kulshreshtha B, Eunice M, Ammini AC. Pubertal development among girls with classical congenital adrenal hyperplasia initiated on treatment at different ages. Indian J Endocrinol Metab. 2012;16(4):599603. PMID: 22837923. PMCID: PMC3401763. https://doi.org/10.4103/ 2230-8210.98018.

16. Sahakitrungruang T. Clinical and molecularreview of atypical congenital adrenal hyperplasia. Ann Pediatr Endocrinol Metab. 2015;20(1):1-7. PMID: 25883920. PMCID: PMC4397267. https://doi.org 10.6065/apem.2015.20.1.1.

17. Moshiri M, Chapman T, Fechner PY, et al. Evaluation and management of disorders of sex development: Multidisciplinary approach to a complex diagnosis. Radiographics. 2012;32(6):1599-618. PMID: 23065160. https://doi.org/10.1148/rg.326125507.

18. Bonfig W, Schwarz HP. Growth pattern of untreated boys with simple virilizing congenital adrenal hyperplasia indicates relative androgen insensitivity during the first six months of life. Horm Res Paediatr. 2011:75(4):264-8. PMID:21196707. https://doi.org/10.1159/ 000322580.

19. Hargitai B, Solyom J, Battelino T, et al. Growth patterns and final height in congenital adrenal hyperplasia due to classical 21hydroxylase deficiency. Results of a multicenter Study. Horm Res. 2001;55(4):161-71. PMID: 11598369. https://doi.org/10.1159/000049990.

20. Rocha RO, Billerbeck AE, Pinto EM, et al. The degree of external genitalia virilization in girls with 21-hydroxylase deficiency appears to be influenced by the CAG repeats in the androgen receptor gene. Clin Endocrinol (Oxf). 2008;68(2):226-32. PMID: 17803691. https://doi. org/10.1111/j.1365-2265.2007.03023.x.

21. Warne GL, Raza J. Disorders of sex development (DSDs), their presentation and management in different cultures. Rev EndocrMetabDisord. 2008;9(3):227-36. PMID: 18633712. https://doi. org/10.1007/s11154-008-9084-2.

Authors are required to accomplish, sign and submit scanned copies of the JAFES Author Form consisting of: (1) the Authorship Certification that the manuscript has been read and approved by all authors, and that the requirements for authorship have been met by each author, (2) the Author Declaration that the article represents original material that is not being considered for publication or has not been published or accepted for publication elsewhere, (3) the Statement of Copyright Transferlaccepted manuscripts become the permanent property of the JAFES and are licensed with an Attribution-Share Alike-Non-Commercial Creative Commons License. Articles may be shared and adapted for non-commercial purposes as long as they are properly cited], (4) the Statement of Disclosure that there are no financial or other relationships that might lead to a conflict of interest. For Original Articles involving human participants, authors are required to submit a scanned copy of the Ethics Review Approval of their research. For manuscripts reporting data from studies involving animals, authors are required to submit a scanned copy of the Institutional Animal Care and Use Committee approval. For Case Reports or Series, and Images in Endocrinology, consent forms, are required for the publication of information about patients; otherwise, authors declared that all means have been exhausted for securing such consent. Articles and any other material published in the JAFES represent the work of the author(s) and should not be construed to reflect the opinions of the Editors or the Publisher. 